\title{
The Epistemic Responsibilities of Citizens in a Democracy
}

\begin{abstract}
The chapter develops a taxonomy of views about the epistemic responsibilities of citizens in a democracy. Prominent approaches to epistemic democracy, epistocracy, epistemic libertarianism, and pure proceduralism are examined through the lens of this taxonomy. The primary aim is to explore options for developing an account of the epistemic responsibilities of citizens in a democracy. The chapter also argues that a number of recent attacks on democracy may not adequately register the availability of a minimal approach to the epistemic responsibilities of citizens in a democracy.
\end{abstract}

Keywords: epistemic responsibility; political ignorance; rational irrationality; epistocracy; epistemic democracy; libertarianism; pure proceduralism; political epistemology; democracy

\section{Introduction}

Does democratic participation come with a responsibility to be informed about politics? What about a responsibility to think rationally, or be open-minded and intellectually virtuous in other ways when engaging in political deliberation? To what extent are ordinary citizens informed, rational, and intellectually virtuous when engaging in politics?

Questions at the intersection of democratic theory and epistemology go back at least as far as Plato, and have remained a central focus of political philosophy throughout history. More recently, they have been taken up in empirically informed ways by political theorists, economists, and cognitive psychologists. For example, a vast empirical literature probes the extent to which citizens of large representative democracies tend to be ignorant ${ }^{1}$ or uninformed about political matters. Numerous other studies examine the cognitive behaviour of individual citizens when deliberating about politics (Brennan 2020; Somin 2020).

\footnotetext{
${ }^{1}$ I use the term "ignorant" to cover both the false belief sense of ignorant and the lack of belief sense. I use the term "irrational" to denote a further epistemic lack, one having to do with lack of evidential support.
} 
This chapter seeks to provide a roadmap through some of this complex terrain. It does so by developing a taxonomy, dividing the terrain into three broad stances on the "epistemic responsibilities" of citizens in a democracy. I call these stances non-epistemicism, optimism, and pessimism. Each stance represents a kind of extreme in a matrix of possible views about the relationship between the epistemic responsibilities, if any, that democratic participation generates for citizens, and the epistemic competences that those citizens have. I examine how recent approaches to epistemic democracy, epistocracy, epistemic libertarianism, and pure proceduralism fit within this three-pronged taxonomy. My main aim is to explore the options for developing an account of the epistemic responsibilities of citizens in a democracy. I also aim to shed light on how there is considerable room for a fairly minimal approach to epistemic responsibilities of citizens in a democracy_one that, in my view, a number of theorists have not adequately registered in their recent attacks on democracy.

\section{The Taxonomy}

John is a citizen of a large representative democracy electing a new federal government. One of the key policy differences between parties in the election concerns action on climate change. As part of his voting deliberations, John has done some careful research on what climate change is and what's causing it. He's also done some research on what each of the parties proposes to do

about climate change. He's thought and discussed open-mindedly and critically with others about how effective each of those proposals would be if adopted. He's done something similar regarding other platform differences on issues he's inclined to find important. As a result of all this research and discussion, John prefers party A over party B, and his vote will reflect this. 
In at least some respects, John is a relatively rare citizen. Not very many of us have the time or energy to be as epistemically diligent in deciding who to vote for. Many of us simply vote for a particular party out of habit, or because of some deep commitment that tends to override specifics on issues of the day (Gabriel Lenz 2012; Mason 2018). Yet there is something intuitive about the idea that John is, at least with respect to these features of his voting behaviour, an example of responsible democratic participation. We can couch the idea that John is an example of responsible democratic participation in terms of the notion of a "political epistemic responsibility" (PER):

PER: a defeasible responsibility to meet certain epistemic criteria in contributing to the democratic decision-making process.

The idea is that John is an example of responsible democratic participation at least partly because he lives up to his PERs, whatever those are exactly.

This definition of a PER is very open-ended. Many of the important details in the discussion to follow concern what these epistemic criteria are, and what the nature of this putative responsibility is, among other things. For example, here is one distinction to draw between two senses of "responsibility" that may be at play when talking about PERs:

$\mathbf{R}($ functional): $\mathrm{X}$ is an $\mathrm{R}$ (functional) responsibility of S's only if $\mathrm{X}$ is a necessary condition S must meet in order to successfully play S's role in contributing to the goal(s), $\operatorname{aim}(\mathrm{s})$, or function(s) of practice $\mathrm{Y}$. 
$\mathbf{R}$ (normative): $\mathrm{X}$ is an $\mathrm{R}$ (normative) responsibility of S's only if $\mathrm{X}$ is a necessary condition S must meet in order to successfully play S's role in contributing to the goals(s), aim(s), or function(s) of practice $\mathrm{Y}$, and $\mathrm{Y}$ ought to be practiced.

Assume for the sake of argument that at least one central aim or goal of democratic decisionmaking is to represent the interests of the majority of citizens (we might have this aim for many reasons - including epistemic ones). If a necessary condition on achieving this aim is that each citizen (or some percentage of citizens) is informed about $\mathrm{P}$ in coming to believe that party A, and not B, will best promote their interests (and voting on that basis), then we might say that being informed about $\mathrm{P}$ is an $\mathrm{R}$ (functional) of those citizens, vis-à-vis this putative aim of democracy. If it turns out this process of democratic decision-making is a practice that genuinely ought to be practiced, perhaps meeting those epistemic conditions is an $\mathrm{R}$ (normative) for those citizens. For the most part, I wish to remain neutral on whether democracy is something that ought to be practiced. So, I leave it an open question whether the responsibilities at play when I speak of PERs are R(functional) or R(normative).

My primary concern is to categorize possible views about the epistemic responsibilities of citizens in a democracy along two broad axes. The first axis is about demands: Does the practice of democratic participation in some way generate PERs? If so, what kind, and for whom? The second axis is about competences: what sorts of epistemic competences do citizens in a democracy actually tend to have? Do they tend to be informed about politics, and/or to deliberate rationally in forming political beliefs? Under what conditions?

If we divide views along each axis into two opposing extremes, we generate three broadly different camps of interest (differences on the epistemic abilities axis between 
proponents of non-epistemicism (those who hold that democratic participation does not generate PERs for citizens) do not really matter for our purposes). Actual views held by political theorists and philosophers about the nature and value ${ }^{2}$ of democracy tend to fall somewhere in a matrix between the extremes represented in the following chart:

\begin{tabular}{|c|c|c|c|}
\hline & \multicolumn{2}{|c|}{ Competences } \\
\hline & & $\begin{array}{l}\text { Citizens tend to be epistemically } \\
\text { competent }\end{array}$ & $\begin{array}{l}\text { Citizens do not tend to be epistemically } \\
\text { competent }\end{array}$ \\
\hline \multirow{2}{*}{$\begin{array}{l}\mathrm{D} \\
\mathrm{e} \\
\mathrm{m} \\
\mathrm{a} \\
\mathrm{n} \\
\mathrm{d} \\
\mathrm{s}\end{array}$} & $\begin{array}{l}\text { Democratic } \\
\text { participation } \\
\text { generates PERs for } \\
\text { citizens }\end{array}$ & $\begin{array}{l}\text { Optimism } \\
\text {-aggregative epistemic democrats } \\
\text {-deliberative epistemic democrats }\end{array}$ & $\begin{array}{c}\text { Pessimism } \\
\text {-epistemic libertarians } \\
\text {-epistocrats }\end{array}$ \\
\hline & $\begin{array}{l}\text { Democratic } \\
\text { participation does } \\
\text { not generate PERs } \\
\text { for citizens }\end{array}$ & \multicolumn{2}{|c|}{$\begin{array}{c}\text { Non-Epistemicism } \\
\text {-pure proceduralists } \\
\text {-classical deliberative democrats }\end{array}$} \\
\hline
\end{tabular}

In the next few sections, I examine forms of non-epistemicism, pessimism, and optimism, highlighting some of the main commitments and motivations of thinkers who've defended views in democratic theory that fit within one or another of these categories.

\section{Non-Epistemicism}

Much recent literature at the intersection of political theory and epistemology focuses on the amount of political ignorance and irrationality we seem to find amongst citizens in large representative democracies. Many of us are familiar with references to survey data detailing a supposedly staggering degree of ignorance about even the most basic "politically relevant" facts

\footnotetext{
${ }^{2}$ Theorists are often interested in more specific issues, such as the legitimacy, authority, or justification of democracy. I wish to remain neutral on those issues, so I simply discuss views insofar as they defend or challenge the claim that democracy is in some broad sense a good idea.
} 
amongst a large percentage of the American electorate. Ilya Somin offers the following claims as paradigm examples: "Much of the time, only a bare majority [of Americans] know which party has control of the Senate, some 70 percent cannot name both of their state's senators, and the majority cannot name any congressional candidate in their district at the height of a campaign" (Somin 2013: 19). “A 2006 Zogby poll found that only 42 percent of Americans could even name the three branches of the federal government: executive, legislative, and judicial" (Somin 2013: 19).

We might take these results to suggest, prima facie, that if citizens have PERs, whatever they are exactly, then citizens must surely fall seriously short of meeting them. We might also wonder what, if anything, should be done about that. I will get to an assessment of the relevance of such survey data to questions about PERs shortly. For now, a natural alternative reaction might be to shrug one's shoulders. Why think citizens have PERs in the first place? From the point of view of the value of democracy, perhaps it's neither here nor there how informed and rational people are about politics (or anything else).

A longstanding tradition in democratic theory defends the value of democracy in terms of the intrinsic value of things like fairness, liberty, and equality. What matters, according to this tradition, is that democratic procedures - authorizing laws by voting, or electing representative legislators - are fair, or respect individual liberty, or have other intrinsically valuable properties. This approach to democratic theory—often referred to as "pure proceduralism"—would seem to entail, or at least leave open, the view about the PERs of citizens in a democracy that I call nonepistemicism.

One form of pure proceduralism is fair proceduralism. The basic idea is that voting is a fair procedure for making collective decisions amongst people who disagree. As long as 
everyone has an equal role to play in determining the outcome, the outcome has value (and may even have the power to render laws legitimate and authoritative), regardless of how we assess it by other, procedure-independent standards.

An advantage of this approach is that it renders unnecessary the potentially messy business of determining what procedure-independent criteria to use in assessing the value of democratically produced outcomes. It also seems immune to worries about voter ignorance. As David Estlund points out: "A procedure can be fair to participants whether or not they are smart, or well informed, or virtuous" (Estlund 2008: 66). For my purposes, this is the main point. The fact that a procedure can be fair, irrespective of facts about epistemic competences of citizens, and the fact that fair proceduralism grounds the value of democratically determined outcomes on the idea that those outcomes are the result of a fair procedure, seems to imply that democratic participation does not, in its own right, generate PERs for citizens. In other words, pure proceduralism — at least of this paradigmatic variety — seems at odds with the idea that there are PERs. Hence it is a kind of non-epistemicism. ${ }^{3}$

\section{Pessimism}

Much recent democratic theory has taken a more instrumentalist turn. There are well-known critiques as well as defenses of democracy that hinge, in part, on an instrumentalist turn. By instrumentalist, I mean the idea that the value of democracy should be judged according to procedure-independent criteria, perhaps in addition to procedural criteria. For example, an instrumentalist might maintain that a democratic decision-making procedure has value only if it

\footnotetext{
${ }^{3}$ Early forms of deliberative democracy emphasise the intrinsic value of a "reasonable exchange" of viewpoints and ideas, where "reasonable exchange" is not intended to be understood with reference to procedure-independent criteria. These approaches might best be classified under non-epistemicism.
} 
is more likely (under certain conditions) to lead to a "correct" outcome than a non-democratic decision-making procedure, such as oligarchy, or dictatorship. Recall John and the difference between party A and party B on climate change. The idea of a correct outcome is that one of these parties has the correct view about what to do about climate change. ${ }^{4}$ Instrumentalists may also focus on the tendency of democracy to produce morally good laws, or other practical benefits. In the remainder of this chapter, I focus on epistemic forms of instrumentalism.

Starting with critiques of democracy, one form of pessimism is embodied in a view we can call "epistemic libertarianism". Epistemic libertarians, such as Ilya Somin (2013) and Bryan Caplan (2007), have argued that we should abandon centralized governments in favour of highly decentralized federal states; we should minimize and localize government, and leave more decision making to the free-market. As Somin puts it, we should minimize centralized governments to make more room for "foot voting", the process by which citizens who dislike the policies they live under pursue improvement by literally moving to a jurisdiction with more favourable policies (Somin 2013: 119-155). The primary basis for their proposals is an epistemic one.

These theorists take the survey data mentioned above very much to heart (Somin 2013: 17-61; Caplan: 50-94). According to epistemic libertarians, if the electorate resembles-even remotely — the picture we get from political knowledge survey data, then that electorate should not be guiding the political decision-making process, at least not in the way it does in a representative democracy. In addition to relying on such survey results, Somin and Caplan

\footnotetext{
${ }^{4}$ We can distinguish between claims about the proper aims of democratic decision-making (e.g. should we reduce human impact on climate change?) and claims about the means to those aims (e.g. how to reduce human impact on climate change?). Many, though by no means all, instrumentalists are wary of talking about correct answers to endstype (value-laden) questions. For sake of space I bracket this issue.
} 
defend the idea that, in societies with large populations and fairly centralized governments, we should expect citizens to be massively politically ignorant and irrational. Epistemic libertarians take a cue from Anthony Downs (1957), arguing that political ignorance is instrumentally rational. According to Downs (and others), the rationality of political ignorance is an upshot of the nature of voting in a representative democracy with millions of voters; it's an upshot of the fact that the chances of an individual citizen's vote being a deciding factor in an election or referendum are near zero. The idea is that this has a significant impact on citizens' incentive to be informed about whatever it is they are voting on. Caplan takes the claim further, arguing it is instrumentally rational for voters to be (epistemically) irrational in forming political beliefs (Caplan 2007: 114-142). The idea is that it makes more sense, from the point of view of practical rationality, to succumb to biases and prejudices that protect one's sense of self and identity, when forming political beliefs, than it does to try to form beliefs that are carefully proportioned to the evidence. According to epistemic libertarians, citizens in smaller, federalized and freemarket driven societies would have greater incentive to remain informed and rational in their political deliberations. ${ }^{5}$

Another form of pessimism is embodied in "epistocracy". Like epistemic libertarians, the most prominent contemporary advocate of epistocracy, Jason Brennan, tends to place a lot of store in survey data about political ignorance, as well as worries about the rationality of citizens in forming political beliefs (often for similar reasons) (Brennan 2016: 23-74; cf. Lopez-Guerra 2014: Ch.2). Brennan differs, however, in the conclusions he draws from these worries. Rather than recommending shrinking government and leaving more decisions to the free market,

\footnotetext{
${ }^{5}$ Some have argued that we should not expect voters to become significantly more informed of about political issues and their governments even if these become downsized and de-centralized (Christiano 2015).
} 
epistocracy recommends adopting legal restrictions on who can vote, how votes are counted, or how individual votes ultimately contribute to democratic decision-making processes. Epistocratic approaches to restricting the franchise range from J.S. Mill's epistocracy of the educated (plural votes for the "educated"), to voter competence exams, to universal suffrage with "epistemic veto", whereby a "cognitively elite" body has the opportunity to veto decisions it deems unjustified or bad (“malicious, incompetent, or unreasonable") (Brennan 2016: 204-231; see Brennan (2020) for a defense of "enlightened preference voting").

Setting the details of these positive proposals aside, both epistemic libertarians and epistocrats suggest a picture according to which it is democracy, or more specifically, the kind of democratic participation involved in large representative democracies, that generates the sorts of PERs that citizens are supposedly not to be able to meet. By advocating for epistocracy, Brennan effectively advocates for a political system in which low-competence citizens no longer have PERs, because they are no longer voters. By advocating for "foot voting", Caplan and Somin effectively advocate for a political system in which low-competence citizens have a lot less to think about (and a lot more incentive to try harder), because they are voting on much more local issues. We can draw out claims about PERs implied by these approaches by thinking about the following question: What sorts of demands would citizens need to meet in order for these pessimists to stop being worried about democracy? Both epistemic libertarians and epistocrats tend to have a fairly stringent view of what constitutes epistemic competence of voters in a democracy. They regard detailed information about government structures, political processes, and economics as relevant (perhaps even central) to our understanding of voter competency. As we'll see below, optimists tend to reject these assumptions about the nature of PERs. 


\section{Optimism}

In stark opposition to both epistemic libertarians and epistocrats, "epistemic democrats" defend democracy in part on the basis of claims about its tendency to produce (epistemically) good decisions. ${ }^{6}$ Epistemic democrats tend to focus on the epistemic benefits of vote aggregation, the epistemic benefits of "deliberation", or some combination of both. Aggregative and deliberative approaches may have different upshots for our understanding of the nature of citizens' PERs.

Starting with aggregative approaches, theorists tend to rely on versions of the Condorcet Jury Theorem (CJT), the "miracle of aggregation", or ways in which the benefits of cognitive diversity can be reaped through aggregation processes. See Heléne Landemore's excellent overview of CJT and the miracle of aggregation in her Chapter in this volume. ${ }^{7}$

Here I will focus on the implications for PERs of the CJT approach, particularly as they arise from the so-called "competence" and "independence" conditions (Landemore 2020). We can draw these out by thinking about the following question: What sorts of demands would citizens need to meet in order for these conditions to be satisfied? Minimally, to satisfy the competence condition, it seems voters must be better than random at "getting things right". The independence condition requires that the probability of one person being right on any binary question must be the same regardless of the probability of another person being right for that same question (Landemore 2013: 73). So, to satisfy the independence condition, it seems citizens must avoid being systematically influenced by others in casting their votes. There are any

\footnotetext{
${ }^{6}$ Not all epistemic democrats presuppose instrumentalism (Peter 2008).

${ }^{7}$ Prominent objections to CJT target the competence and independence conditions, along with other requirements such as that voters must be sincere, and that political decisions have correct outcomes. Robert Goodin and Kai Spiekermann (2018) build on classical versions of CJT, largely in response to these sorts of worries, resulting in a complex version of aggregative democracy (see also Landemore 2016: p.149-156, for an accessible, qualified defense).
} 
number of things we might take this to imply about the PERs of individuals — perhaps it corresponds with a demand of intellectual autonomy, or intellectual courage (Fairweather forthcoming).

Despite the fact that according to these approaches much of the epistemic work is done by aggregation itself, citizens have a role to play at the individual level. To make this more vivid, note that the competence condition is cast in terms of probabilities of being right. There are at least two dimensions relevant to that probability: the individual's abilities, and the environment in which they find themselves. When it comes to the latter dimension, note how hostile the epistemic environment is for citizens gathering political information: news outlets often put a great deal of spin on their reporting, personalization algorithms influence access to social media, politicians have agendas that can affect their presentation of information, and so on (Battaly 2020). Even if citizens tend to have a high degree of epistemic competence, the probability of choosing the correct option may nevertheless be quite low, given this hostile environment. In this regard, perhaps the competence condition places a more stringent epistemic demand on individuals than it at first seems (cf. Worsnip 2018).

Let's turn to deliberative forms of epistemic democracy. "Deliberation" refers to the process of exchanging reasons and argumentation with the aim of reaching a decision. Deliberation takes place in many contexts - from within one's own mind, to between citizens, to between elected legislators, and so on. In reality, decisions in a democracy are never reached through deliberation alone. At some point, a non-deliberative decision procedure, such as voting, must be used to settle residual disagreement. But the idea that deliberative epistemic democrats typically embrace is that deliberation: 
- Enlarges the pools of ideas and information.

- Weeds out good arguments from the bad.

- Leads to a consensus on the "better" or "more reasonable" solution.

(Landemore 2013: 97)

Epistemic democrats such as Landemore $(2013,2020)$ and James Bohman $(2006)$ emphasize that we shouldn't expect deliberation, all by itself, to do these things; rather, deliberation must take place under constraints, which defenders of deliberative epistemic democracy argue democratic institutions can provide. In particular, it's widely thought that diversity and inclusiveness are necessary conditions on the epistemic benefits of deliberation. Typically, not much is said in terms of specifics about what sorts of epistemic competences individuals must have for a deliberative process to achieve anything like i)-iii). There is also much controversy over the question of whether deliberation really is likely to do i), ii), or iii), or whether any of i)-iii) is necessary or sufficient for deliberation to reap the epistemic benefits claimed by epistemic democrats.

One strategy for teasing out implications of deliberative epistemic democracy for our understanding of PERs is to look at some of the most compelling arguments against the epistemic benefits of deliberation, and ask: What sorts of demands would citizens need to meet in order for these arguments to fail? Hannon (forthcoming) has recently summarized a number of well-known arguments against the epistemic benefits of deliberation, highlighting empirical arguments for the pervasiveness of phenomena such as group polarization (Sunstein 2002), cultural cognition (Kahan et. al 2011), and motivated reasoning in a political deliberative context (Haidt 2012). If these really are a threat to the epistemic benefits of deliberation, then, minimally, 
it would seem an epistemic demand on citizens, according to deliberative epistemic democracy, is that citizens have the epistemic competences needed (perhaps only after certain kinds of training) to render these threats unproblematic. However stringent PERs would have to be in this regard seems difficult to precisely specify. But this gives us at least a basic sense of the interaction between deliberative epistemic democracy and our understanding of PERs.

Some proponents of the epistemic benefits of deliberation may be prepared to grant that individual citizens tend to fit the profile ascribed to them by those who advance these objections, but maintain that deliberation has epistemic benefits nonetheless. The idea is to argue that the epistemic benefits of deliberation are the result of collective or distributed features of deliberation, as opposed to facts about individuals involved. Landemore (2013) focuses on "models of cognitive diversity" (drawing on work by Lu Hong and Scott Page) to argue that, in both a deliberative and aggregative context, the epistemic value of democracy is not so much a function of individual epistemic ability, as it is "cognitive diversity" (understood as a plurality of modes of thinking and interpretations of the world) (Landemore 2020).

On this latter picture, the main (epistemic) lesson of deliberative epistemic democracy for individuals is something like: be yourself! This is an upshot of the idea that the more diverse the deliberating group is, the better. There is a limit to the value of diversity—not all views should be taken into account—-but this far from imagining that being a good citizen requires citizens to be up to date on the latest political issues, to have encyclopaedic knowledge of the mechanisms and structure of government, and a firm grasp of economics. The epistemic benefits of deliberation are such that, when large groups of people, with many different perspectives on an issue, contribute to the process of exchange of reasons, that group is likely to produce a better 
outcome than any subset of the group would produce (at least over time, over a long chain of decisions).

\section{Hybrid Views}

Some prominent defenses and critiques of democracy may not fit neatly within my taxonomy. To illustrate with just one example, start with the observation that the optimists and pessimists we've discussed so far have presupposed a "veritistic" conception of the epistemic benefits and drawbacks of democracy. Veritistic epistemic goods are epistemic goods that derive their value from the value of truth.

Michael Hannon (forthcoming) has recently argued for a shift in focus towards nonveritistic goods, such as "empathetic understanding". Empathetic understanding is the ability to take up another person's viewpoint, to be able to see why another person believes what they do (forthcoming: 9). Hannon's view is motivated by a worry shared by many of the pessimists discussed above, namely that there are serious grounds for concern about citizens' ability to be informed and rational in their political decision-making. But perhaps we shouldn't see such goods as the aim of deliberative structures and processes in the first place. Another way of thinking about the epistemic goods that democratic participation both requires and tends to promote is in terms of empathetic understanding. ${ }^{8}$ To understand others, we need to empathize with their thinking, and this minimally requires:

- Being willing to listen.

\footnotetext{
${ }^{8}$ Hannon couches his epistemic defense of democracy in terms of epistemic benefits to individuals, as opposed to epistemic benefits democracy has for society's decision-making as a whole. See Hannon (forthcoming: 21) for discussion of whether empathetic understanding really is a non-veritistic epistemic good.
} 
- Having the ability to take up another person's perspective.

Hannon argues that, provided citizens meet these conditions, democratic deliberation will promote empathetic understanding amongst the citizenry (which may in turn promote other good things). And that might be one reason to think deliberative democracy is a good idea, in comparison with other democratic models, such as pure aggregation models. According to this picture, we might say that the PERs of citizens in a democracy include a responsibility towards empathetically understanding other citizens. As Hannon acknowledges, there is room for debate about whether empathetic understanding is a genuinely epistemic good (forthcoming: 20). If one were to disagree about that, then, given his skepticism about veritistic forms of deliberative epistemic democracy, we might be tempted to place him somewhere on a hazy line between pessimism and non-epistemicism. ${ }^{9}$

\section{What Counts as Competence, and How It's Determined}

As we've seen, pessimists tend to rely on survey data about political ignorance in challenging democracy, in addition to a priori arguments about the incentives of voters. There are a number of interconnected issues we can raise about this sort of reliance on survey data, as well as these a priori arguments.

Arthur Lupia (2016) has argued that a good deal of work needs to be done by pessimists to articulate a clear logic getting them from claims about survey data, to claims about voter competence (see esp. Ch 15 and 16). A closely related issue surrounds the use of "political

\footnotetext{
${ }^{9}$ Anne Jeffreys' "limited epistocracy" (2018) and David Estlund's (2008) "epistemic proceduralism" strike me as other potential hybrid views.
} 
knowledge scales" to arrive at conclusions about citizens' political knowledge. Surveys such as the American National Elections Studies (ANES) simply aggregate the scores of individuals' answers to a small set of questions about politics. While these questions are chosen for specific reasons - presumably with the aim of making them representative of "political knowledge"Lupia argues that there is simply no evidence that political knowledge scales like those of the ANES are representative of anything we can fairly label "political knowledge". Rather, they may well be representative of much more specific kinds of knowledge (and ignorance), which, as Lupia also argues, may or may not be a necessary or sufficient condition on having a high-value competence relevant to democratic participation (Lupia 2016: Ch. 16). The basic issue here is about how the term "political knowledge" tends to be operationalized in various studies (cf. Landemore 2013: 199-200). ${ }^{10}$

Optimists have much to say about how citizens who don't know much about the sorts of things asked on political-knowledge surveys can contribute valuably to the democratic process. Often, (as seen with Landemore) authors focus on how informational and cognitive processes in a democracy are distributed. Others rely more heavily on claims about citizen use of "information shortcuts", heuristics enabling people to make the same decisions with respect to some set of options that they would if they were "fully informed" about the options. Examples of information shortcuts frequently discussed in the literature include: party identification,

\footnotetext{
${ }^{10}$ Additional issues in this area include how survey questions are posed, and the context in which questions are asked. For example, significant differences arise when participants are offered a dollar for each correct answer to a survey question, or given 24 hours to respond (Prior \& Lupia 2008: 169). Also, the way accuracy of participant answers is measured is crucial. What counts as a "correct" answer or "nearly correct" answer to certain questions can sometimes be fuzzy to interpret (Lupia 2016: 209).
} 
retrospective evaluations of the economy, and relying on opinion leaders (for influential work on this topic, see Popkin 1994; Robertson 1976; Lupia \& McCubbins 1998).

Thomas Christiano, a prominent defender of democracy against empirically-based worries about voter ignorance and irrationality, focuses on the division of intellectual labour and the use of information shortcuts in democratic societies; he's developed an expansive account of the resources available to citizens in contributing to the democratic process $(2015 ; 2018)$. Christiano points to the fact that real-world political deliberation happens across numerous levels, from citizens, to experts, to opinion leaders, and politicians. Each level plays a different role in deliberation, requiring different kinds of intellectual capacities. Real-world polities rely on a stratification of deliberative tasks. Even within levels - at the level of ordinary conversations amongst citizens about politics, for example - people can rely on one another (along with other information shortcuts) in a division of intellectual labour. For example, John might happen to know a good deal about climate change, but not much about foreign policy. John's friend Linda might be in the opposite position. Christiano suggests that, as long as certain conditions are met—such as each person having relevant background knowledge about the other-John and Linda can reasonably trust one another's say-so when it comes to politically relevant factual information on these topics. As externalists in epistemology are well aware, lacking the ability to positively justify one's beliefs on a given topic need not undermine the possibility that one's beliefs are warranted (Christiano 2015: 261).

We can also push back on Downsian claims about incentives of voters to be informed and rational when voting in large representative democracies. Mackie (2012) has argued that Downs' idea presupposes a mistaken model of why people vote in the first place. Mackie argues for a "contributory model", according to which the aim of voting isn't merely to get someone to win, 
but also to show that whoever you're voting for, even if they lose, has a certain mandate behind them.

There is of course much room for debate about the efficacy of mechanisms for the division of cognitive labor, as well as voter incentives to be informed. ${ }^{11}$ But this section has canvassed some ways one might challenge the degree of stringency assumed in many pessimistic views about PERs. Moreover, it has explained why, even if pessimists are right about stringency, it's far from clear that we have an accurate picture of whether or to what extent citizens really do tend to fall short of their PERs.

\section{Conclusion}

We have identified a number of important choice points for our understanding of PERs of citizens in a democracy.

- Views may differ on the question of whether PERs are R(normative) or merely $\mathrm{R}($ functional) responsibilities.

- They may also differ on the question of stringency—for instance, on the extent to which technical, detailed information about government structures, political processes, and economics are relevant to voter competence.

- There may also be room for debate about whether PERs should be understood in veritistic or non-veritistic terms.

By placing some prominent views in democratic theory within the three-pronged distinction between non-epistemicism, pessimism, and optimism, we have been able to draw out these possibilities, while keeping their broader implications for our understanding of democracy in

\footnotetext{
${ }^{11}$ For a helpful summary of some compelling pessimistic responses, see (Somin 2015: 386-389).
} 
view. I have also suggested that there is room for a fairly minimal approach to PERs — one that, in my view, many pessimists do not always seem to pay adequate attention to in their attacks on democracy.

\section{References}

Brennan, J. (2016) Against Democracy, Princeton: Princeton University Press. (2020) "In Defense of Epistocracy: Enlightened Preference Voting," in M. Hannon \& J. de Ridder, The Routledge Handbook of Political Epistemology, Routledge.

Bohman, J. (2006) “Deliberative Democracy and the Epistemic Benefits of Diversity," Episteme, 3(3): 175-191.

Caplan, B. (2007) The Myth of the Rational Voter, Princeton: Princeton University Press.

Downs, A. (1957) An Economic Theory of Democracy, New York: Harper.

Estlund, D. (2008) Democratic Authority: A Philosophical Framework, Princeton: Princeton University Press.

Fairweather, A. (Forthcoming) "Intellectual Courage", in H. Battaly (ed.), The Routledge Handbook of Virtue Epistemology. Routledge.

Goodin, R. \& Spiekermann, K. (2018) An Epistemic Theory of Democracy, Oxford: Oxford University Press.

Haidt, J. (2012). The righteous mind: Why good people are divided by politics and religion, Vintage.

Hannon, M. (Forthcoming) "Empathetic Understanding and Deliberative Democracy," Philosophy and Phenomenological Research.

Jeffrey, A. (2018) “Limited Epistocracy and Political Inclusion,” Episteme, 15(4): 412-432. 
Kahan, D.M., Jenkins-Smith, H. \& Braman, D. (2011) “Cultural cognition of scientific consensus," Journal of Risk Research 14(2): 147-174.

Landemore, H. (2013) Democratic Reason: Politics, Collective Intelligence, and the Rule of the Many, Princeton: Princeton University Press.

(2020) “An Epistemic Argument for Democracy,” in M. Hannon \& J. de Ridder, The Routledge Handbook of Political Epistemology, Routledge.

Lenz, G. (2012). Follow the Leader? How Voters Respond to Politicians' Policies and

Performance. Chicago: University of Chicago Press.

Lupia, A. (2016) Uninformed: Why People Know so Little about Politics and What We Can do about It, Oxford: Oxford University Press.

Lupia, R. \& McCubbins, M. (1998) The Democratic Dilemma: Can Citizens Learn What They Need to Know? Cambridge: Cambridge University Press.

Mackie, G. (2012) “Rational Ignorance and Beyond,” in J. Elster \& H. Landemore (eds.), Collective Wisdom: Principles and Mechanisms, Cambridge: Cambridge University Press.

Mason, L. (2018). Uncivil Agreement: How Politics Became Our Identity. Chicago: Chicago University Press.

Peter, F. (2008) “Pure Epistemic Proceduralism,” Episteme, 5(1): 33-55.

Popkin, S. (1994) The Reasoning Voter, Chicago: University of Chicago Press.

Prior, M. \& Lupia, A. (2008) “Money, Time, and Political Knowledge: Distinguishing Quick Recall and Political Learning Skills," American Journal of Political Science, 52(1): $169-183$. 
Robertson, D. (1976) “Surrogates for Party Identification in the Rational Choice Framework," in I. Budge (ed.), Party Identification and Beyond: Representations of Voting and Party Competition, London: Wiley.

Somin, I. (2013) Democracy and Political Ignorance, Stanford: Stanford University Press. (2015) “The Ongoing Debate Over Political Ignorance: Reply to My Critics,” Critical Review, 27(3-4): 380-414. (2020) “Is Political Ignorance Rational?” in M. Hannon \& J. de Ridder, The Routledge Handbook of Political Epistemology, Routledge.

Sunstein, C. (2002) “The Law of Group Polarization," Journal of Political Philosophy, 10(2): $175-195$.

Worsnip, A. (2018) “The Obligation to Diversify One’s Sources: Against Epistemic Partisanship in the Consumption of News Media," in C. Fox \& J. Saunders (eds.), Media Ethics: Free Speech and the Requirements of Democracy, Abingdon: Routledge. 